\title{
DEMOCRACIA, ARENAS DECISÓRIAS E POLÍTICA ECONÔMICA NO GOVERNO LULA
}

\author{
Maria Rita Loureiro \\ Fábio Pereira dos Santos \\ Alexandre de Ávila Gomide
}

\section{Introdução}

As escolhas políticas que levaram as novas democracias a se inserirem na economia global têm trazido exigências paradoxais para seus governos. De um lado, o modelo de integração internacional impõe a necessidade de gerar confiança e credibilidade para os mercados financeiros com relação à capacidade de solvência governamental, e, portanto, restriçôes fiscais. De outro lado, a democratização e a maior liberdade de expressão das demandas populares por políticas redistributivas empurram os governantes em outra direção. Dessa forma, a dinâmica democrática nesses países faz com que os governos, ao definirem seus rumos, levem em conta não apenas as exigências do mercado, mas também as demandas mais amplas da sociedade

Artigo recebido em março/2010

Aprovado em fevereiro/2011 (crescimento, expansão do emprego, distribuição de renda), fundamentais para sua legitimação política (Przeworski, 1995; Sola, 2004).

O objetivo deste texto é discutir os impactos na agenda macroeconômica, particularmente na área fiscal, deste processo duplo de transformaçōes que desafiam os governos das chamadas democracias de mercado emergente (Whitehead, 2002). A escolha da temática fiscal merece esclarecimento. De modo geral, ela costuma ser foco privilegiado por economistas ortodoxos e políticos conservadores. Desde as crises dos anos de 1970-1980, analistas atacavam as políticas keynesianas e os gastos com programas sociais do Welfare State com a retórica de que o déficit público era o resultado de gastanças irresponsáveis dos governos, exprimindo a falta de compromisso moral em face das gerações futuras (Buchanan, Rowley e Tollison, 1987).

Questionando tais pressupostos ideológicos, a presente análise distancia-se da visão conservadora 
e leva em conta várias pesquisas empíricas que revelaram o fracasso das políticas ortodoxas destinadas a zerar o déficit público. Tanto nos Estados Unidos como nos países europeus foram grandes as dificuldades políticas para reduzir os déficits públicos na situação de recessão econômica e de desemprego que caracterizou os anos de 1980. Os estudos mostraram que a maioria dos países só conseguiu equilibrar seus problemas fiscais quando ocorreram novos ciclos de expansão econômica. Provavelmente, foi esse quadro de dificuldades econômicas e políticas que levou os mentores da comunidade econômica europeia, no tratado de Maastricht, a estabelecer um teto de 3\% do PIB para o déficit nominal, abandonando a meta do déficit zero (Schich, 1993; Brady e Volden, 1998; Briffault, 1996; Evans, 1997). Em tempos mais recentes, a crise financeira global desencadeada em 2008 tem ajudado a reforçar as críticas ao conservadorismo econômico e político.

O presente texto se distingue ainda das análises convencionais porque procura enfatizar a questão fiscal pelo prisma político e, mais particularmente, a partir das possibilidades trazidas pela democracia. A literatura produzida na economia, especialmente na área de finanças públicas, muitas vezes supõe que a lógica democrática traz obstáculos ou constrangimentos à "racionalidade econômica" e às iniciativas de ajuste fiscal. ${ }^{1}$ Ao contrário, argumentamos que a democracia permite melhorar a qualidade das políticas públicas (tornando-as mais representativas e próximas às demandas sociais) e aumentando, assim, a probabilidade da eficácia de sua implementação.

Recorrendo-se à própria história brasileira das últimas décadas, pode-se relembrar que foi sob o regime democrático que se alcançou o ordenamento das contas públicas legadas em profunda desordem pela ditadura militar. As eleiçōes regulares, o sistema de poder descentralizado pelo federalismo e pelo multipartidarismo não têm sido obstáculos para o desenvolvimento de um processo gradual de mudanças na área fiscal. Independentemente de julgamentos de valor acerca do conteúdo destas políticas, destaca-se aqui que os processos democráticos não têm sido empecilhos à efetivação de mudanças consideráveis nesta área no país. Em outras palavras, o poder compartilhado não tem sido obstáculo à governabilidade, como a literatura convencional sustenta. Novas abordagens teóricas têm permitido explicar que políticas públicas formuladas de forma negociada com os atores políticos relevantes e implementadas gradualmente têm mais chances de sucesso do que as decididas de forma intempestiva em arenas restritas e insuladas do restante do sistema político e das demandas da sociedade.

Diferentemente de concepções (formuladas com frequência em bases apenas dedutivas) que veem nessa situação de desconcentração de poder uma limitação à governabilidade e propõem arranjos decisórios de tipo majoritários ou mais centrípetos, pesquisas empíricas mais recentes têm mostrado situações inversas. A partir de estudos quantitativos, Lipjhart (1999) mostrou que o sistema político mais consociativo (em que o poder está menos concentrado) é não só mais representativo em sociedades heterogêneas, mas também não tem sido obstáculo à gestão macroeconômica, em especial ao controle da inflação. Outros autores, como Stark e Brustz (1998), ao examinarem as bases institucionais da coerência (ou sustentabilidade temporal) das políticas econômicas adotadas em países do Leste Europeu no pós-socialismo, indicam que a capacidade de elaborar e implementar programas de reforma mais eficazes é aumentada quando o Poder Executivo é menos concentrado, ou seja, quando é mais constrangido a prestar contas de suas decisões às diversas forças políticas no parlamento e na sociedade organizada. E, portanto, tem sua responsabilidade política (acccountability) mais estendida. Tendo que debater e negociar suas propostas com outros atores, os decisores aumentam a compreensão dos problemas, ampliam a capacidade de obter informações, corrigindo erros de cálculo que, na ausência desse processo, só apareceriam no momento da implementação, e, portanto, com menor possibilidade de correção. Isto encoraja, ainda, os formuladores a pensar vários passos à frente nos jogos estratégicos das políticas públicas, além de comprometer e responsabilizar mais atores políticos com os resultados dos programas adotados. Em suma, o argumento desenvolvido por essa literatura (e que 
endossamos aqui) é que a democracia pode funcionar como uma oportunidade e não um obstáculo à gestão macroeconômica adequada (em outras palavras, como enabling e não como desenabling constraints).

Com relação à questão fiscal no Brasil, cabe lembrar que ela tem estado em nossa agenda pública há quase três décadas, mas com objetivos cambiantes. Nos anos de 1980-1990, ela estava focada nas reformas institucionais destinadas ao ordenamento das contas públicas, de modo geral bem-sucedidas, como a unificação dos orçamentos, a criação da Secretaria do Tesouro Nacional, a estabilização monetária, a reestruturação do sistema bancário público e privado. A partir de 1999, concentrou-se na política de geração de superávits primários que tem servido de garantia de solvência para o mercado, também consolidando, com a Lei de Responsabilidade Fiscal, medidas mais severas de controle dos gastos e do endividamento público, particularmente para os governos subnacionais.

No primeiro governo Lula, sob o comando do ministro da Fazenda Antônio Palocci, a política macroeconômica caracterizou-se pela continuidade em relação à orientação predominante no governo Fernando Henrique Cardoso, e a política fiscal, em particular, foi marcada pela intensificação do nível do superávit primário e ainda por propostas de déficit nominal zero. Todavia, o segundo governo apresentou mudanças, com o lançamento do programa de aceleração do crescimento (PAC), a expansão do sistema de crédito consignado para bens de consumo, a ampliação dos programas de transferência de renda, a concessão de aumentos reais para o salário mínimo, além de novas contratações e aumentos salariais para o funcionalismo público. Tais mudanças indicam que a política fiscal deixou de ser apenas um instrumento de garantia de solvência para os credores (credibilidade financeira) e adquiriu também o papel de instrumento de política de crescimento econômico e de melhoria da distribuição de renda.

Como tais mudanças da política fiscal ocorreram e como elas podem ser entendidas na dinâmica da democracia brasileira? Em outras palavras, o que possibilitou o adensamento da agenda fiscal no governo Lula, permitindo que ela passasse também a responder às demandas por crescimento econômico e transferência de renda?

Em primeiro lugar, cabe destacar o timing dessas mudanças. Elas ocorreram predominantemente a partir do segundo mandato, quando o governo já havia conseguido provar aos investidores que iria cumprir as promessas efetuadas durante a campanha de 2002 na "Carta ao Povo Brasileiro".Além disso, o novo clima internacional - que, mesmo antes da eclosão da crise financeira de 2008, já apresentava indícios de questionamento da agenda liberal e de seus impactos nos países em desenvolvimento - repercutiu fortemente no Brasil. ${ }^{2} \mathrm{E}$ foi reforçado com a divulgação de informações econômicas do país no final de 2006, indicando níveis bastante baixos de crescimento econômico.. Por fim, a substituição da equipe econômica por outra mais distante da ortodoxia que prevaleceu no $\mathrm{Mi}$ nistério da Fazenda no primeiro mandato também é fator relevante na flexibilização da agenda fiscal do segundo governo Lula.

Com relação à forma ou estilo decisório na área fiscal, é possível afirmar que também houve mudanças no segundo governo Lula, e essas se processaram no padrão típico de nosso presidencialismo de coalizão (Abranches, 1988). Exigindo negociação constante entre os atores políticos com poder de veto, essa modalidade de sistema político acaba levando à segmentação da burocracia: de um lado, núcleos decisórios insulados que garantem a realização do programa de governo, especialmente as políticas econômicas; ${ }^{3}$ de outro, arenas abertas à pressão e à negociação de diferentes atores políticos. Pode-se mesmo definir essa segmentação como procedimento quase típico de nossa democracia presidencialista, na medida em que foi praticada, tanto no quadro institucional de 1946-1964, no segundo governo Vargas e no governo JK (D’Araújo, 1982; Geddes, 1994) como no marco pós-1988 nos mandatos de Fernando Henrique Cardoso (Loureiro e Abrucio, 1999).

No caso do segundo governo Lula, essa segmentação manifestou-se na impermeabilidade da política monetária do Banco Central às pressões do sistema político mais amplo e, de outro lado, na abertura para negociaçōes na política fiscal. Além do Ministério da Fazenda, outras agências governa- 
mentais (como Casa Civil, BNDES etc.) passaram a fazer parte das arenas decisórias, o que permitiu a ampliação do conteúdo da política. Em outras palavras, o adensamento da política fiscal, desdobrando-se para além do objetivo de gerar credibilidade para o mercado financeiro e incluindo também crescimento do emprego, da renda, do crédito etc. foi possível pela ampliação da arena decisória e pela adoção de estilo mais negociado de tomada de decisão.

Todavia nunca é demais frisar que a tendência de mudança da agenda fiscal chega até o limite em que não ameace os interesses da coalizão política dominante no país, centrada no capital financeiro e em grupos "rentistas" (o chamado "poder de fogo do mercado"). Politicamente, essa coalizão tem se expressado na ação dos dirigentes do Banco Central, respaldada pelo mainstream dominante na comunidade epistêmica (organismos internacionais, universidades norte-americanas e nacionais, empresas de consultoria etc.) e difundida constantemente na mídia. ${ }^{4}$ Do ponto de vista econômico a coalizão sustenta-se na dependência estrutural do Estado em relação ao setor financeiro para a rolagem da dívida pública interna, já que parte significativa da dívida mobiliária federal é composta por títulos de curto prazo baseados na taxa Selic, detidos majoritariamente pelas instituiçôes financeiras. $\mathrm{Na}$ composição desses interesses incluem-se até mesmo fundos de pensão de importantes segmentos sindicalizados da classe trabalhadora brasileira, como os bancários e os petroleiros, que são base de sustentação do próprio Partido dos Trabalhadores.

É pertinente relembrar, para reforço deste argumento, a literatura que discute os momentos de autonomia do Estado em relação aos capitais privados. Ela aponta as tensôes existentes entre as políticas sociais, redistributivas, e aquelas voltadas a garantir condições seguras de acumulação de capital, especialmente na arena financeira (Skocpol, 1985). Como argumentou Przeworski (1995), em situações em que o capital é internacionalmente móvel a teoria da dependência estrutural do Estado ao capital pode ser aplicada. A atual dependência estrutural do Estado brasileiro ao setor financeiro internacionalizado é resultado das escolhas efetuadas no passado e reafirmadas no presente. Dessas escolhas decorrem as exigências paradoxais entre acumulação financeira e legitimação política, configurando situação em que as políticas destinadas a atender demandas sociais devem se submeter à necessidade de garantir a solvência governamental. Assim, as políticas sociais e de desenvolvimento econômico só avançam até o limite em que não contrariam a credibilidade exigida pelo mercado financeiro. A despeito desse limite, eles não deixam de fazer diferença na configuração política e econômica do país na última década.

O texto a seguir está assim organizado. Inicialmente há uma breve descrição da trajetória da agenda fiscal no Brasil ao longo das três últimas décadas, destacando seus pontos principais de inflexão gerados pelas crises externas e dinâmicas políticas internas. Em seguida, comparam-se as agendas macroeconômicas do PT antes e durante a experiência à frente do governo federal, destacando-se o período Palocci, em que há a continuidade do receituário liberal e mesmo tentativas de aprofundá-lo, com a proposta de déficit nominal zero. $\mathrm{Na}$ terceira parte, examina-se como o segundo governo Lula opera a dupla face da política fiscal e concilia suas ambivalências. As considerações finais procuram sistematizar os argumentos.

\section{A trajetória da agenda fiscal no Brasil}

\section{Do descalabro da ditadura ao ordenamento das contas}

Durante o regime militar, o poder do Congresso Nacional de legislar sobre questôes de financiamento público foi transferido para um órgão da burocracia governamental, o Conselho Monetário Nacional (CMN). Este tinha total poder para administrar a dívida mobiliária sem que as operaçôes transitassem pelo Orçamento Geral da União (OGU). Em consequência do descrédito do OGU, que não tinha capacidade para impor limites e restrições à política fiscal, surgiram orçamentos paralelos que eram submetidos apenas ao Executivo, como, por exemplo, o orçamento monetário. $\mathrm{Na}$ verdade, durante as décadas do governo militar, as finanças do setor público brasileiro eram norteadas 
por uma grande multiplicidade orçamentária. Além do OGU, havia o orçamento monetário, a conta da dívida e ainda o orçamento das empresas estatais. ${ }^{5}$

$\mathrm{O}$ orçamento monetário funcionava como uma ferramenta de controle do passivo monetário e não monetário que era utilizado para a política cambial, para autorizar subsídios e linhas de crédito a diferentes setores de atividade econômica e outros programas. Cada orçamento era aprovado por uma autoridade pública diferente e em momentos também diferentes, o que causava total desarticulação entre as políticas econômicas implementadas pelo governo. $\mathrm{O}$ orçamento monetário era um artifício jurídico/contábil que funcionava como uma espécie de ralo por onde vazavam os recursos do Tesouro, em ações como crédito à agricultura e às exportações e na política de preços mínimos agrícolas (OCDE-Brasil, 2001).

Além disso, havia a estratégia, adotada pelos governos de utilização das autoridades monetárias como bancos de fomento do desenvolvimento econômico, como forma de viabilizar a política de "crescimento com endividamento". Grandes volumes de recursos eram levantados sem elevar a carga tributária, ou seja, sem desestabilizar politicamente o regime militar vigente. A contrapartida era sempre a expansão monetária ou elevação da dívida mobiliária (Idem).

$\mathrm{Na}$ verdade, do ponto de vista monetário, além do Banco Central (Bacen), também o Banco do Brasil (BB) operava na área, disputando e ganhando poder em relação ao Bacen. Quando este foi criado em 1964, o BB, que até então exercia funções de autoridade monetária, era uma agência extremamente forte na estrutura de poder do país. Tal poder permitiu-lhe reter parcela considerável de atribuições de política econômica, gerando assim uma situação esdrúxula de duas autoridades monetárias em concorrência e, consequentemente, de ausência de controle efetivo da política monetária. $\mathrm{O}$ BB passou a ser o titular da chamada "conta-movimento", instituída para processar o nivelamento das reservas com o Bacen. Tratava-se de um passivo do $\mathrm{BB}$ em relação ao Bacen, inventado para suprir sua falta de infraestrutura administrativa e técnica no período inicial de atividades. Embora criada para ser um expediente provisório a vigorar apenas no momento de transição institucional, essa conta acabou sendo perpetuada por facilitar a liberação de empréstimos e financiamentos sem que estes constassem do orçamento do governo. Em outras palavras, a conta-movimento permitia ao BB sacar sem limites contra o Tesouro, inviabilizando qualquer controle fiscal. Além disso, na ausência de uma Secretaria do Tesouro, o governo não tinha meios de saber, de fato, como andavam suas contas (Gouvea, 1994; OCDE-Brasil, 2001).

Como se não bastasse, havia a conta da dívida que, a partir do início da década de 1970, funcionou de forma autônoma e garantiu a cobertura dos juros e amortizaçōes (serviço da dívida) sempre por meio da emissão de novos títulos. Esse processo ficou conhecido como o "giro da dívida interna". A dívida crescia em função de diversos fatores, do seu próprio serviço e do financiamento de gastos extra-orçamentários, nunca se sabendo, ao certo, o quanto era devido a cada fator (OCDE-Brasil, 2001).

Esta era a situação da área fiscal até a crise que atinge as economias capitalistas nos anos de 1970/1980, desencadeada por vários fatores, entre eles o choque dos preços do petróleo que repercute nos países periféricos, como o Brasil, sob a forma de uma grave crise de dívida externa. Como se sabe, essa crise levou ao esgotamento do modelo de desenvolvimento econômico fundado no endividamento externo crescente (Bresser-Pereira, Maravall e Przeworski, 1993). A situação das finanças públicas no Brasil agravou-se ainda mais, gerando outro sério problema fiscal: o do aval da União a qualquer empréstimo externo efetuado pelos estados, municípios e empresas estatais, honrados pelo BB através do Orçamento Monetário. Também os aportes de recursos aos bancos estaduais passaram a ser supridos por esta Conta-movimento do Banco do Brasil (OCDE-Brasil, 2001). ${ }^{6}$ Embora tenham ocorrido, sob pressão dos organismos internacionais, tentativas de ordenamento das finanças públicas ainda sob o governo militar, elas não surtiram efeito (Gouveia, 1994).

Portanto, foi tal quadro caótico - no qual era impossível qualquer controle eficaz sobre o orçamento público, a política monetária e o endivida- 
mento do governo e das estatais - que a ditadura e a gestão tecnocrática da economia legaram ao país. Se fatores macroestruturais de ordem econômica e situações da conjuntura internacional tiveram impactos na geração deste quadro, não se pode deixar de enfatizar que a desorganização das finanças públicas brasileiras foi profundamente acentuada pelo caráter autoritário do governo, dado que não havia controle público democrático das decisões altamente insuladas tomadas pela tecnocracia econômica.

Medidas de ordenamento das finanças governamentais, tais como a unificação dos orçamentos, a criação de órgãos de controle das contas públicas como a Secretaria do Tesouro Nacional (STN) e regras mais rigorosas sobre endividamento público só ocorreram após a redemocratização, na segunda metade dos anos de 1980 e ao longo da década seguinte. A consolidação dessas medidas, bem como a centralização da autoridade monetária no Banco Central só se efetivaram após a implementação do Plano Real, a partir de 1994, e com a adoção de reformas econômicas voltadas à estabilização monetária. Na verdade, para melhor compreender a trajetória da agenda fiscal no Brasil, é necessário situá-la dentro da própria trajetória da agenda neoliberal no país.

\section{$A$ adoção da agenda neoliberal}

Como se sabe, a abertura comercial trazida pelo governo Collor, em 1990, desencadeia o processo gradual de rompimento com o modelo de substituição de importações, predominante no Brasil no período do nacional-desenvolvimentismo (iniciado com Vargas e consolidado nos governos militares). Este modelo foi gradualmente desmontado pelas políticas econômicas dos anos de 1990, especialmente no governo FHC: abertura financeira, eliminação dos monopólios estatais nos setores de petróleo, energia e telecomunicações, privatizações de numerosas empresas e bancos públicos. Além do processo de estabilização monetária, com o Plano Real, é necessário destacar também outras mudanças menos conhecidas, mas igualmente significativas ocorridas ao longo destes anos. Elas envolvem a informatização das contas públicas e seu maior ordenamento e transparência, a renegociação das dívidas dos governos subnacionais com a lei 9.496 de 1997, a efetivação dos programas de reestruturação dos bancos públicos e privados (Proer e Proes) e ainda a criação de sistemas mais sólidos de proteção e fiscalização bancária (Sola e Kugelmas, 2002; Marques, 2005).

Esta experiência trouxe uma nova cultura política para o país, na qual a estabilização monetária se tornou o maior objetivo da política macroeconômica desde então. Como se sabe, a convivência com altas taxas de inflação, que caracterizou boa parte da história econômica brasileira na segunda metade do século passado, gerou impactos perversos para as finanças públicas e para parcelas da sociedade (Sola e Kugelmas, 2002), com perdas para as camadas de mais baixa renda sem contas bancárias e sem acesso à correção monetária de seus salários. Para os governos, a crônica hiperinflação significava que o orçamento era uma "peça de ficção", como se costumava dizer, pois impossibilitava o planejamento de receitas e gastos e qualquer tipo de transparência e controle das contas públicas.

Todavia, se a política econômica do primeiro governo FHC foi bem-sucedida no tocante à estabilidade de preços, ela se mostrou insustentável devido à acumulação contínua de passivos públicos e externos. Embora o Plano Real tivesse colocado o ajuste fiscal como seu eixo fundamental e identificado o desequilíbrio das contas públicas como a causa fundamental da alta inflação, não houve ajuste fiscal "prévio" ou simultâneo à estabilização. Ela só veio a se consolidar após a crise de 1999, por imposição do FMI. Diante da vulnerabilidade, manifestada de forma dramática com a crise externa de 1998 que levou à desvalorização do Real em janeiro de 1999 e que explicitou os limites da política econômica adotada até então, o segundo mandato de FHC teve que produzir mudanças. Como são bem conhecidas, tais mudanças apoiaram-se no tripé: 1) adoção do regime de metas de inflação; b) câmbio flutuante; e c) ajuste fiscal voltado para a geração de superávits primários - estes necessários à garantia de confiança dos credores na solvência do governo, devido ao aumento da despesa com juros, desencadeado pela instabilidade financeira (Oliveira e Turolla, 2003). 


\section{A agenda fiscal no governo Lula}

Os documentos programáticos do Partido dos Trabalhadores apresentados antes da campanha de 2002 eram relativamente vagos sobre o regime de política fiscal a ser adotado em caso de vitória eleitoral. Ainda assim, é possível perceber que as críticas à política adotada por FHC deslocavam-se de uma rejeição completa ao "arrocho fiscal" para a preocupação crescente com a "viabilidade" das medidas a serem implementadas em um eventual governo de Lula. O elevado endividamento público, seu perfil de curto prazo e os gastos com juros eram entendidos como restrições fundamentais a serem consideradas em uma possível reorientação da política fiscal em direção a um modelo "redistributivo e indutor do crescimento". ${ }^{7}$

Enfatizando a perspectiva de mudança, os programas do PT faziam menções genéricas à necessidade de aumentar os gastos públicos em políticas de habitação, saneamento e infraestrutura e, ainda, elevar o investimento das estatais, especialmente nas áreas de energia. Mesmo rejeitando a simples volta ao modelo nacional desenvolvimentista, eles propunham retomar algumas estratégias para reativar o papel do Estado na economia (agora como indutor e coordenador) com o objetivo de alcançar o pleno emprego e universalizar as políticas sociais. Ênfase especial era também atribuída aos bancos públicos federais no que concerne ao investimento, expansão do crédito e formação de poupança obrigatória, como FGTS (Fundo de Garantia de tempo de Serviço) e FAT(Fundo de Amparo ao Trabalhador).

Entre os documentos formulados durante a campanha, o mais importante foi a "Carta ao Povo Brasileiro", que representou o compromisso explícito do então candidato Lula com o superávit primário, garantindo uma taxa estável de endividamento ante o PIB. Esse compromisso, de fato incorporado posteriormente no programa de governo, foi fundamental para acalmar os credores e o mercado financeiro, na medida em que se intensificavam, na competição eleitoral, o medo e as expectativas negativas sobre o que ocorreria em um governo do PT. Ele foi decisivo para a vitória de Lula.

Não entrando na controvérsia relativa à continuidade ou ruptura do governo Lula em relação às políticas defendidas na campanha, é relevante enfatizar outro ponto: se a continuidade da política econômica de Lula com relação à do segundo mandato de FHC pode ser interpretada como um desfecho possível ou mesmo previsível da trajetória programática do PT, o que causa surpresa, entretanto, é o fato de que o primeiro mandato de Lula tenha sido uma radicalização da política fiscal de FHC.

\section{A proposta de radicalização da ortodoxia fiscal}

Em abril de 2003, o Ministério da Fazenda lança o documento intitulado "Política econômica e reformas estruturais", apresentando a opção da agenda econômica daquele momento: equilíbrio fiscal, focalização das políticas sociais e reformas estruturais (como a reforma da Previdência Social).

No que se refere à política fiscal, o documento afirma que foram os graves desequilíbrios das últimas décadas geradores de inflação e aumentos da relação dívida líquida/PIB. Esse indicador da solvência do setor público que chegou a $56 \%$ em 2002 acarretou o aumento da desconfiança na capacidade do governo em honrar seus compromissos futuros, levando aos maiores prêmios de risco dos títulos da dívida pública e ao aumento da taxa de juros. Por isso, o primeiro compromisso da política econômica do governo foi resolver o problema fiscal. Assim, adotaram-se medidas para produção de maiores e continuados superávits primários $(4,25 \%$ do PIB), necessários para assegurar a redução gradativa da relação dívida/PIB. Peso maior foi dado ao ajuste fiscal sob o pressuposto de que ele condicionaria as principais variáveis macroeconômicas, como a taxa de inflação, as taxa de juros e a taxa de câmbio. A condução de parte desse receituário permitiu o recuo da taxa de inflação, que tinha chegado a $12,5 \%$ em 2002, e a diminuição da taxa de juros, que estava no patamar de $27 \%$ no começo de 2003 (ou seja, em 16\% em termos reais).

Complementando essa agenda, o Ministério da Fazenda divulga, no final de 2004, outro documento, intitulado "Reformas microeconômicas e crescimento de longo prazo", que expressa o entendimento de que a política macro deveria ser completada pelas reformas microeconômicas. Estas en- 
fatizam a importância das condições institucionais para o adequado funcionamento do mercado, a melhoria do ambiente de negócios, além das reformas trabalhistas e regulatórias. No que concerne ao ambiente de negócios, destacam-se as medidas de ampliação dos mecanismos para o financiamento da infraestrutura, como a lei das parcerias público-privadas, aprovada pelo Congresso Nacional.

Ademais, em 2005, desenvolveu-se dentro do governo a proposta de zerar o déficit nominal num curto horizonte de tempo (em torno de cinco anos), como forma de acelerar a diminuição da relação dívida/PIB. A implantação de tal proposta, no entanto, exigiria medidas consideradas "penosas", no curto e médio prazo. Muitas delas por meio de emenda constitucional, como forma de "amarrar as mãos do governo" (ou de sinalizar o credible commitment), "blindando-o" de mudanças políticas, e evitar o chamado stop and go da política fiscal.

O programa do déficit nominal zero propunha as seguintes medidas: elevação da meta de superávit primário para $5 \%$ do PIB; desvinculação das receitas da União (em saúde e educação principalmente) dos atuais $20 \%$ para $35 \%$ do orçamento; congelamento real do custeio da máquina pública, principalmente de salários e contrataçôes ("choque de gestão"); e uma nova rodada de reforma previdenciária, para diminuição do chamado "déficit previdenciário", via desvinculação dos benefícios ao salário mínimo e da revisão para cima da idade limite para a aposentadoria. Em suma, essa proposta, claramente marcada pelo aprofundamento da ortodoxia neoliberal, projetava a possibilidade de o Brasil crescer 5\% apenas em 2017.

O início da discussão pública da proposta, ocorreu junto com a crise política de 2005, conhecida na mídia como "mensalão". Essa crise, como se sabe, provocou a troca do comando da Casa Civil da Presidência da República. A ministra Dilma Rousseff, que então assumiu a Casa Civil, passou a participar também das decisões em matéria econômica. Com relação à ideia de déficit zero, a nova ministra, em entrevista à imprensa, imediatamente a desclassificou, definindo-a de "rudimentar" e, portanto, retirando-a da agenda econômica. A ruptura com essa proposta de radicalização da política fiscal, por sua vez, foi reforçada com a substituição de Palocci por Guido Mantega à frente do Ministério da Fazenda. ${ }^{8}$ Em outubro de 2006, no contexto da reeleição do presidente Lula, o então ministro das Relações Institucionais chegou a afirmar que "a era Palocci” (que marcou os três primeiros anos do governo Lula) havia acabado. O fim da "era Palocci” representou não apenas a inflexão da política fis$\mathrm{cal}$, mas igualmente a ampliação da arena decisória, como se indicará a seguir.

\section{A política fiscal no segundo governo Lula}

No debate eleitoral que levou à reeleição de Lula em 2006, discutiu-se a dificuldade do modelo macroeconômico, praticado desde 1999, em promover o crescimento da economia. Nesse contexto, o presidente encomenda à Casa Civil e ao Ministério da Fazenda a elaboração de um conjunto de medidas para "destravar" a economia, atingir a meta de crescimento do PIB de 5\% já em 2007 e para todo o segundo mandato. Contudo, a mudança no discurso da política econômica não se processou sem contestações, havendo opositores à sua inflexão dentro do próprio governo, que cobravam a manutenção da orientação anterior e mesmo o aprofundamento do ajuste fiscal. ${ }^{9}$

Juntamente com o pífio desempenho da economia (que apresentava taxas inferiores a $2 \%$ de crescimento anual), as mudanças no Ministério da Fazenda e a nova liderança da Casa Civil foram fatores decisivos para uma reorientação das diretrizes prevalecentes na chamada "era Palocci”. A participação da Casa Civil no comando da gestão econômica significou maior abertura desta arena decisória a outros atores políticos, uma vez que é o espaço institucional de articulação entre o Executivo e o Legislativo e entre o governo federal e os governos subnacionais. Também houve troca de comando em outras áreas importantes da administração econômica, como no BNDES, cujo presidente, com mais legitimidade política, pôde intensificar a orientação de apoio às políticas de cunho desenvolvimentista e, portanto, mais abertas a negociações com grupos econômicos privados.

$\mathrm{Na}$ verdade, a flexibilização da equação ortodoxa se dá no segundo governo, quando gradati- 
vamente se acentuam as mudanças iniciadas de forma mais tímida em 2003. Houve a ampliação e extensão dos programas de transferência de renda que cresceram paulatinamente ao longo dos dois mandatos. A expansão sistemática do salário mínimo real que cresceu cerca de $65 \%$ acima da inflação foi muito significativa para a elevação da demanda interna. ${ }^{10}$ Assim foi também a expansão do crédito, especialmente o consignado, considerado "uma revolução na estrutura do crédito no país" . ${ }^{11}$ Iniciativa da Central Única dos Trabalhadores (CUT), o crédito consignado foi fruto de acordo entre sindicatos e bancos. Posteriormente, ele foi estendido para os servidores públicos e aposentados do INSS. Também houve aumento do crédito para empresas e governos subnacionais (com a capitalização e os empréstimos do Tesouro ao BNDES e a flexibilização das autorizações para operações de crédito de prefeituras e estados) que permitiram a ampliação do investimento. É interessante destacar que todas essas iniciativas puderam ser realizadas sem necessidade de mudanças legais. Na verdade, em confronto com ativismo institucional do governo FHC, o governo Lula trouxe mudanças na política fiscal e nos indicadores de desempenho econômico mesmo sem realizar grandes modificações no aparato institucional da área. Assim, o governo Lula desafiou a visão convencional não só ao afirmar que "é possível ter uma aceleração do crescimento mantendo a inflação sob controle", mas também ao inverter na prática a seguinte fórmula: em vez de extremado ajuste fiscal ser a condição para o crescimento, é o crescimento que fortalece o equilíbrio fiscal. $\mathrm{O}$ maior crescimento, aumentando as receitas públicas, permitiu manter a agenda de superávits primários necessários à diminuição progressiva da relação dívida/PIB e à sustentação da credibilidade no mercado financeiro. Ademais, o crescimento também gerou recursos para um relativo aumento dos investimentos públicos, sem necessidade de redução de gastos correntes (em pessoal, programas sociais, como o Bolsa Família, e previdência social). Por fim, mas não menos importante, o crescimento econômico e a elevação do emprego formal permitiram também que se prescindisse da reforma na área previdenciária, a qual implicaria redução de benefícios sociais. A condução do tema da refor- ma previdenciária é, na verdade, outro indício da mudança de foco na política fiscal. No início do segundo governo, foi instituído um fórum que, no final dos trabalhos, decidiu de forma consensual que a Previdência Social deveria continuar sendo parte integrante do conceito de seguridade social e que seu financiamento seria feito com recursos de contribuições dos trabalhadores e empregadores, e seus elementos redistributivos financiados por recursos do orçamento da seguridade social, conforme previsto na Constituição Federal. Mesmo não havendo consenso sobre regras de idade mínima e de tempo de contribuição para acesso a benefícios, os integrantes do fórum - composto de representantes de trabalhadores, empregadores e governo conseguiram estabelecer acordo com relação à permanência da vinculação dos benefícios assistenciais ao salário mínimo - item cuja modificação é considerada fundamental pelos economistas ortodoxos. Em outras palavras, as conclusōes foram claramente contrárias às propostas de viés fiscalista e levaram ao abandono da agenda da reforma tributária. Do ponto de vista político, a retomada da agenda desenvolvimentista foi a chave capaz de atender a todas as constituencies do governo, sem infringir a nenhuma delas perdas econômicas e, portanto, custos políticos.

O lançamento do PAC, em janeiro de 2007, no início do segundo mandato pode ser compreendido nesses termos. Visando prioritariamente ao investimento público em infraestrutura, o programa estabelece também medidas de desoneração e mudanças do sistema tributário e ações fiscais de longo prazo. Pode-se afirmar que por intermédio do PAC o governo começa a atribuir à política fiscal função adicional, ou seja, mesmo garantido o superávit primário fixado, utiliza o espaço para uma política de crescimento, criando, por exemplo, a possibilidade de abater da meta de superávit primário de 4,25\% gastos com investimentos nos Projetos Piloto de Investimento (PPI) de até 0,5\% do PIB e, posteriormente, de abater gastos do próprio PAC.

As medidas de ativação da demanda fizeram emergir gradualmente uma nova configuração na área econômica. Mesmo não sendo novidade histórica, no segundo mandato, o governo transformou 
as políticas sociais em políticas econômicas. Incorporando o receituário keynesiano, foi obtendo a clara percepção de que a expansão do consumo permitiria expandir a produção e gerar crescimento econômico. ${ }^{12} \mathrm{Ou}$ seja, o bem-estar dos pobres não é apenas um problema para a caridade privada ou para os programas assistenciais que recebem verbas residuais do orçamento público. Ele se transforma em fonte decisiva de crescimento econômico.

Com a crise financeira internacional de 2008, as políticas expansionistas destinadas a recuperar o nível de atividade econômica tiveram um reforço adicional, destacando-se dois grupos de medidas. O primeiro visou gerar provisão de liquidez ao sistema financeiro, por meio da redução dos depósitos compulsórios, criação de financiamento de curto prazo às exportações e desoneração de vários setores. O segundo grupo procurou atuar em dimensões mais estruturais, com o lançamento do programa habitacional dirigido para a população de baixa renda (Minha Casa, Minha Vida), mobilizando os bancos públicos que assumiram política ativa de expansão do crédito e procuraram, assim, compensar o "atraso" da política monetária em estimular a recuperação econômica. Embora os sinais da crise já estivessem desenhados no horizonte, o Copom iniciou, em janeiro de 2008, um novo ciclo de elevação da taxa de juros, argumentando eventual possibilidade de recrudescimento da inflação. ${ }^{13}$ A explosão da crise em setembro de 2008 tampouco gerou a redução rápida da taxa de juros; ao contrário, esta se manteve elevada (no patamar de $13,75 \%$ ao ano) até janeiro de 2009 , quando inicia lenta trajetória de queda.

Mesmo considerando que durante a crise financeira de 2008 o insulamento de núcleo decisório da política monetária no Banco Central tenha se mantido, as mudanças das políticas econômicas - responsáveis pelos indicadores positivos de crescimento econômico, elevação da taxa de emprego, redução da pobreza e da desigualdade - são significativas. E, como interessa ressaltar nesse texto, elas têm a ver não só com a conjuntura de crise econômica, mas igualmente com a ampliação do núcleo decisório e, consequentemente, com a maior accountability dos decisores a um leque maior de atores políticos.

\section{Considerações finais}

Segundo a literatura convencional, a abertura das arenas decisórias às pressôes de eleitores ou às demandas sociais compromete os objetivos estabelecidos para as políticas macroeconômicas que, frequentemente, implicam a aplicação de "pílulas amargas" à população (elevação de taxas de juros, cortes em gastos públicos, redução dos programas sociais etc.). Por essa razão, considera-se necessária a concentração de poder de decisão em mão de técnicos ou burocratas que não precisam se apresentar em campanhas eleitorais. Ou seja, é necessário o insulamento dos policymakers para que as políticas possam ser corretamente formuladas e efetivamente implementadas e seus objetivos não sejam deturpados pelo populismo, clientelismo e a irresponsabilidade que, nessa visão caracterizam necessariamente todos os atores políticos, uma vez que esses dependem do voto popular e do apoio de grupos de interesse que sustentam suas campanhas.

Neste trabalho, argumentou-se em outra direção. $\mathrm{O}$ insulamento burocrático não é a solução para os chamados "males" da política. Ao contrário da retórica de seus patrocinadores, ele não é de forma nenhuma um processo técnico e apolítico (Nunes, 1997). No caso do Banco Central, sua impermeabilidade às pressōes que lhe tem permitido praticar política de juros elevados há mais de uma década não se explica por uma ideia abstrata "de racionalidade econômica”, por uma lógica estritamente técnica e neutra, como muitos afirmam. Trata-se de política imposta pelo chamado "poder de fogo" do mercado financeiro, que pode constranger os governos que se financiam através do endividamento público interno ou externo, impondo-lhes a "autonomia" (se não legal, pelo menos, de fato) da autoridade monetária, "protegendo-a" contra pressões do restante do sistema político e, portanto, gerando credible commitment.

Ademais, contrariando ainda a visão convencional, mostrou-se que a consolidação democrática, mesmo sob a forma de presidencialismo de coalizão, que exige negociaçôes continuadas entre uma pluralidade de atores (com partidos no Legislativo e com os governos subnacionais), não foi obstáculo à efetivação das políticas de estabilidade monetária 
e de ordenamento das contas públicas que lograram sucesso no Brasil dos anos de 1990. Também a regularidade do processo eleitoral tem sido fator fundamental para que os temas do crescimento e de redistribuição de renda passassem a ser incorporados na agenda pública brasileira dos anos 2000. A eleição de Lula em 2002, sua reeleição em 2006 e, sobretudo, o segundo mandato, orientado por políticas de estímulo ao crescimento e de expansão da demanda interna, são expressivos desse processo.

Mesmo que tais políticas permaneçam subordinadas ao modelo macroeconômico baseado no tripé de metas de inflação, câmbio flutuante e superávit primário, as mudanças são relevantes. Elas indicam que, a despeito dos limites impostos pelo mercado financeiro, na era da mobilidade dos capitais, há espaços para escolhas de políticas que também atendam às demandas sociais, como as aqui mencionadas.

Contudo, se os processos eleitorais são fundamentais em uma ordem democrática, eles não são suficientes para o aprofundamento da democracia. Como vários teóricos contemporâneos têm apontado, não só os mecanismos de escolhas de governo, mas também as formas de se tomar decisões, com arranjos institucionais que aumentem a responsabilização política dos governantes, são fundamentais para a efetivação dos princípios democráticos. A extensão da responsabilidade política envolvendo um leque mais amplo de atores, durante todo o mandato (e não apenas nos momentos eleitorais), é necessária e supõe, inclusive, o aperfeiçoamento da capacidade de fiscalização das ações dos governantes: além dos sistemas tradicionais de checks and balances, ela contempla também novos experimentos de controle social no qual se possa exercer o chamado "poder negativo do demos" - "que não só autoriza, mas também pode destituir seus representantes" (Held, 2006; Urbinati, 2006).

Por fim, cabe assinalar o padrão de continuidade e mudança, típico da tradição política brasileira e presente na estratégia do governo Lula. Ele consistiu na realização de projetos historicamente adiados - inclusão de grandes contingentes populacionais no mercado de consumo e início do processo de redução da desigualdade de renda - por meio de adaptações às circunstâncias para abrir brechas na estrutura de poder, de modo pragmático, isto é, sem enfrentamentos radicais. Essa estratégia (e não apenas seus resultados) tem certamente impactos significativos para o aprofundamento da democracia representativa no Brasil. Todavia, o dimensionamento de tais impactos só poderá ser avaliado de forma consistente por novas pesquisas orientadas pela teoria democrática contemporânea.

\section{Notas}

1 Belluzzo sintetiza a visão de economistas conservadores nos seguintes termos: "O mal é a politica. Se o Estado se limitasse a cumprir os seus deveres de guardião da livre-concorrência, de bom administrador das finanças e da moeda, um discreto provedor de 'externalidades', mediante o investimento em infraestrutura, tudo correria às mil maravilhas" (1999, p. 18).

2 Essas críticas partiam não só de dissidentes como Stiglitz (2000), mas também de dirigentes dos organismos internacionais como Strauss-Kahn (2008).

3 Olhando a experiência brasileira, podemos observar com a ajuda de ampla literatura que as políticas econômicas têm sido basicamente formuladas no interior da burocracia do Executivo, "protegidas" pelo respaldo do presidente da República contra as pressões (vindas do sistema partidário, do próprio Congresso e da sociedade civil organizada). Estas arenas são compostas não somente de altos funcionários, mas também de acadêmicos de prestígio e de economistas vindos do mercado financeiro que se tornam temporariamente dirigentes ou assessores governamentais, com amplos poderes para formular e implementar medidas ou programas econômicos. (Souza, 1976; D'Araujo, 1982; Martins, 1985; Loureiro, 1997; Diniz, 1997; Sola, 1998). Embora tais traços tenham emergido em regimes autoritários, eles estão igualmente presentes na atual ordem democrática, que atribui grande poder institucional ao Executivo através de medidas provisórias e controle sobre a execução orçamentária (Mainwaring, 1997; Figueiredo e Limongi, 1999).

4 Como se indicará a seguir, no primeiro governo Lula, também o Ministério da Fazenda pautava-se por orientações calçadas nesta visão. Para a discussão do conceito de coalizão de interesses e seus processos de formação e sustentação, ver Sabatier (2007).

5 Até o final dos anos de 1970, as receitas e as despesas das empresas estatais não haviam sido agregadas em um 
orçamento consolidado. Somente com a criação da Secretaria de Controle das Empresas Estatais (SEST), em 1979, é que o governo começa a ter um conhecimento um pouco menos precário do número total de entidades estatais e fazer um orçamento geral das empresas estatais para o ano seguinte (Martins, 1985).

6 Devido à elevação das taxas de juros internacionais no início dos anos de 1980, tornou-se insustentável o processo de financiamento externo da economia brasileira: o pagamento de juros atingiu US\$ 13 bilhões em 1982, o que equivalia a $82 \%$ das exportaçôes, e o déficit em conta corrente representava mais de $5 \%$ do PIB (OCDE-Brasil, 2001).

7 "Concepção e Diretrizes do Programa de Governo do PT para o Brasil”, aprovadas em dezembro de 2001 no Encontro Nacional do PT. Embora com críticas duras ao governo FHC, o documento traz também a preocupação de sinalizar uma crítica "à esquerda": "teremos de romper com o voluntarismo utópico e ingênuo que tantas vezes entusiasmou e frustrou as propostas históricas da esquerda brasileira”. O eixo da crítica à política econômica é o aumento da vulnerabilidade externa da economia brasileira, em especial a perda de autonomia do país para fazer política macroeconômica.

8 Palocci saiu do Ministério da Fazenda devido à quebra ilegal do sigilo bancário da conta-poupança do caseiro Francenildo dos Santos Costa, que acusou Palocci de frequentar a mansão alugada em Brasília pela chamada "República de Ribeirão Preto".

9 Em novembro de 2006, por exemplo, a diretoria de Estudos Macroeconômicos do Ipea divulga "Uma agenda para o crescimento econômico e a redução da pobreza", no qual reafirma a agenda da "era Palocci". O texto argumentava que só por meio de medidas fiscais duras e penosas o país conseguiria fazer crescer o PIB em 5\% - e isto apenas a partir de 2017 (Levy e Villela, 2006).

10 Isso se considerada a variação estimada entre 31/12/2002 ( $\mathrm{R} \$ 200,00)$ e 31/12/2010 (R\$ 510,00). $\mathrm{O}$ índice de crescimento do salário mínimo varia conforme a escolha de critério. $\mathrm{O}$ mais adequado seria o valor real médio de 2002 comparado com o valor real médio de 2010.

11 Segundo o banqueiro Roberto Setubal, "o Brasil não precisa de reformas. Essas não são prioritárias para sustentar o elevado crescimento econômico de 2010 pelos próximos anos. Grandes reformas como a tributária, a trabalhista e a política 'param o país' e não necessariamente servem para alterar tanto. Imagina uma reforma trabalhista: O Brasil iria parar para discussões intermináveis que, ao final, poderiam nem alterar tanto as coisas. Medidas pontuais são mais efetivas. Veja o caso da criação do crédito consignado que produziu uma revolução em termos de crédito à pessoa física no Brasil" (Declarações publicadas no jornal Valor Econômico, em 22/10/2010, p. A5, grifo nosso).

12 Como vários teóricos e políticos da social democracia europeia já tinham percebido, o keynesianismo significou politicamente que o bem-estar dos pobres é um problema e também uma solução para a economia. León Blum já dizia na França dos anos de 1930: "uma melhor distribuição [...] reviverá a produção e ao mesmo tempo fará justiça” (Przeworski, 1989, p. 246).

13 O Copom (Comitê de Política monetária) é um colegiado composto pelo presidente e por diretores do Banco Central, encarregado de executar as metas de inflação. Estas são estabelecidas pelo Conselho Monetário Nacional que, por sua vez, tem, desde 1994, uma composição também restrita: presidente do Banco Central, ministro da Fazenda e ministro do Planejamento.

\section{BIBLIOGRAFIA}

ABRANCHES, S. (1988), "Presidencialismo de coalizão: o dilema institucional brasileiro. $\mathrm{Da}$ dos: Revista de Ciências Sociais, 31 (1): 5-34.

Belluzzo, L. G. (1993), "Economia, Estado, democracia”. Revista Lua Nova, 28-29: 201-208 (1999), "Prefácio", in G. Mantega e J. M. Rego (orgs.), Conversas com economistas brasileiros II. São Paulo, Editora 34.

BENEVIDES, M. V. (1976), Governo Kubitschek: desenvolvimento econômico e estabilidade politica. São Paulo, Brasiliense.

BRADY, D. \& VOLDEN, C. (1998), Revolving gridlock: politics and policy from Carter to Clinton. Boulder, Westview Press.

BRESSER PEREIRA, L. C.; MARAVALL, J. M. e PRZEWORSKY, A. (1993), Economic reforms in new democracies. Cambridge, Cambridge University Press.

BRIFFAUL, R. (1996), Balancing acts: the reality behind state balanced budget requirements. Nova York, The Twentieth Century Fund Press.

BUCHANAN, J.; ROWLEY, C. \& TOLLISON, R. (1987), "Government by red ink", in 
ckwell.

(eds.), Deficits, Oxford, Basil Bla-

D'ARAUJO, M. C. (1982). O segundo governo Vargas: democracia, partidos e crise política. Rio de Janeiro, Zahar.

DINIZ, Eli. (1997), Crise, reforma do Estado e governabilidade. Rio de Janeiro, Fundação Getulio Vargas

EVANS, G. (1997), Red ink. The budget, deficit, and debt of US government. San Diego/Londres, Academic Press.

FIGUEIREDO, A. C. \& LIMONGI, F. (1999), Executivo e Legislativo na nova ordem constitucional. Rio de Janeiro/São Paulo, FGV/Fapesp.

GEDDES, B. (1994), Politicians's dilemma: building state capacity in Latin America. Berkeley, University of California Press.

GOUVEIA, G. (1994), Burocracia e elites burocráticas no Brasil. São Paulo, Pauliceia.

HELD, D. (2006), Models of democracy. Stanford, California, Stanford University Press.

IBRE. (1999), "Competição é a chave". Conjuntura Econômica, jul., pp. 3-5.

INSTITUTO DA CIDADANIA. (2001), "Um outro Brasil é possível”. Disponível em <www. estadao.com.br>, acessado em 18 de junho.

LEVY, P. M. \& VILLELA, R. (2006), "Agenda para o crescimento econômico e a redução da pobreza”. Texto para Discussão Ipea n. 1234, Rio de Janeiro, nov.

LIPJHART, A. (1999), Patterns of democracy: government forms and performance in thirty-six countries. New Haven/Londres, Yale University Press.

LOUREIRO, M. R. (1997), Os economistas no governo: democracia e gestão econômica. Rio de Janeiro, FGV.

. (1999). "Política e burocracia no presidencialismo brasileiro: o papel do Ministério da Fazenda no primeiro governo Fernando Henrique Cardoso". Revista Brasileira de Ciências Sociais, 41 (14): 69-89.

LOUREIRO, M. R. \& ABRUCIO, F. L. (2004), "Política e reformas fiscais no Brasil recente". Revista de Economia Política, 24 (1): 50-72

MAINWARING, S. (1997), "Multipartism, robust federalism and presidentialism", in S. Mainwa- ring e M. Shugart, Presidentialism and democracy in Latin America, Cambridge, Cambridge University Press.

MARQUES, M. (2005), Reformas financeiras liberalizantes em democracias emergentes de mercado: o caso do Brasil. São Paulo, tese de doutorado, FFLCH/USP.

MARTINS, L. (1985), Estado capitalista e burocracia no Brasil pós-64. São Paulo, Paz e Terra.

Ministério da Fazenda. (2003), Política econômica e reformas estruturais. Brasília, Ministério da Fazenda. (2004), Reformas microeconômicas e crescimento de longo prazo. Brasília, Ministério da Fazenda.

NUNES, E. (1997), A gramática politica do Brasil: clientelismo e insulamento burocrático. Rio de Janeiro, Zahar.

OCDE-BRASIL. (2001), Estudos econômicos do OCDE: Brasil(2000-2001). Rio de Janeiro, OCDE/FGV.

OLIVEIRA. G. \& TUROLLA, F. (2003), "Política econômica do segundo governo FHC: mudança em condiçôes adversas". Tempo Social, 15 (2): 195-217.

PALOCCI, A. (2002), "Entrevista". Teoria e Debate, 51, jun.-jul.-ago. Disponível em <http:// www.fundacaoperseuabramo.org.br/td/td $51 /$ td51_palocci.htm>.

PINHEIRO, A. C. (1999). "Privatização no Brasil: por quê? Até onde? Até quando? Rio de Janeiro/BNDES. Disponível em <www.bndes.gov. br>.

PRZEWORSKi, A. (1995), Estado e economia no capitalismo. Rio de Janeiro, Relume-Dumará. (1989), Capitalismo e social democracia. São Paulo, Companhia das Letras.

SABATIER, P. (2007), Theories of the policy process. Boulder, Westview Press.

SANTOS, W. G. (2006), O ex-Leviatã brasileiro: do voto disperso ao clientelismo concentrado. Rio de Janeiro, Civilização Brasileira.

SCHICH, A. (1993), "Governments versus budget deficits", in K Weaver e B. Rockman, Do institutions matter? Governmnet capabilities in the United States and abroad, Washington, D. C., The Brookings Institution. 
SINGER, A. (2009), "As bases sociais e ideológicas do lulismo". Novos Estudos Cebrap, 85: 85-102.

SKOCPOL, T. (1985), "Bringing the state back. in: strategies of analysis in current research", in Peter Evans, Dietrich Rueschemeyer e Theda Skocpol, Bringing the state back in, Cambridge, Cambridge University Press.

SOLA, L. (1998), Ideias econômicas e decisões politicas. São Paulo, Edusp/Fapesp. . (2004), "Financial credibility, legitimacy and political discretion: Lula da Silva government, first year". Trabalho apresentado no IV Annual Meeting of Brazilian Political Science Association, Rio de Janeiro.

SOLA, L. \& Kugelmas, E. (2002), "Estabilidade econômica e o Plano Real como construção política e democratização, in L. Sola, E. Kugelmas e L. Whitehead, Banco central, autoridade política e democratização: um equilíbrio delicado, Rio de Janeiro, FGV.

SOLA, L.; KUGELMAS, E. \& Whitehead, L. (2002), Banco central, autoridade politica e democratizaçâo: um equilíbrio delicado. Rio de Janeiro, FGV.

STARK, D. \& BRUSTZ, L. (1998), “Enabling constraints: fontes institucionais de coerência nas políticas públicas no pós-socialismo". Revista Brasileira de Ciências Sociais, 13 (36): 13-39.

STIGLITZ, J. (2000), "O que aprendi com a crise mundial”. Revista de Economia Política, 20: 169-174.

STRAUSS-KAHN, D. (2008), "Em defesa de um estímulo fiscal”. Folha de S. Paulo, 01/2/2008.

URBINATI, N. (2006), "O que torna a representação democrática? Lua Nova, 67: 191-228.

WHITEHEAD, L. (2002), "O delicado equilíbrio entre credibilidade financeira e responsabilização política: reestruturando a autoridade monetária em novas democracias", in L. Sola, E. Kugelmas e L. Whitehead, Banco central, autoridade política e democratização: um equilíbrio delicado, Rio de Janeiro, FGV.

WOLF, M. (2008), "Os limites da liberalização". Valor Econômico, 26 mar., p. A15. 


\section{DEMOCRACIA, ARENAS \\ DECISÓRIAS E POLÍTICA ECONÔMICA NO GOVERNO LULA}

\section{Maria Rita Loureiro, Fábio Pereira dos Santos e Alexandre de Ávila Gomide}

Palavras-chave: Governo Lula; Democracia; Arenas decisórias; Política fiscal; Burocracia.

O texto analisa as características da política fiscal no governo Lula, enfatizando seu conteúdo e estilo decisório, em perspectiva comparada, ou seja, fazendo o confronto com governos anteriores e ainda entre seus dois mandatos. A análise é contextualizada no quadro dos desafios trazidos pela inserção do país na economia global e pela ampliação das demandas sociais permitidas pela nova ordem democrática. Indica-se que a despeito dos limites impostos pelo mercado financeiro que exigem credibilidade financeira diante dos investidores e, portanto, restriçōes fiscais e altos níveis de superávits primários, há espaços para que a política fiscal também se oriente para outros objetivos: estímulo ao crescimento e à expansão da demanda interna, por meio de programas de transferência de renda. Isso foi possível, em grande parte, pela ampliação das arenas decisórias governamentais e pela adoção de estilo mais negociado de tomada de decisão.

\section{DEMOCRACY, DECISION- MAKING ARENAS, AND ECONOMIC POLICY IN LULA'S ADMINISTRATION}

\section{Maria Rita Loureiro, Fábio Pereira dos Santos, and Alexandre de Ávila Gomide}

Keywords: Lula's Administration; Democracy; Decision-making arenas; Fiscal policy; Bureaucracy.

This paper analyzes the characteristics of the fiscal policy in Lula's government, emphasizing its content and decisionmaking style in a comparative perspective, both with prior governments and between his two terms in office. The analysis is contextualized in the framework of the challenges introduced by the international integration model adopted in Brazil during the 1990s and by the expansion of social demands brought by the new democratic order. In spite of limits imposed by financial markets that ask for credibility, fiscal restrictions and high levels of primary surplus, the paper points out that there is room to orienting the fiscal policy towards other goals: economic growth and internal demand stimulus by means of income transfer programs. That was made possible, to a great extent, by the expansion of governmental decision-making arenas and by the adoption of a style of decision-making based more on negotiations.

\section{DÉMOCRATIE, ARÈNES DÉCISOIRES ET POLITIQUE ÉCONOMIQUE DANS LE GOUVERNEMENT LULA}

\section{Maria Rita Loureiro, Fábio Pereira dos} Santos, and Alexandre de Ávila Gomide

Mots-clés: Gouvernement Lula; Démocratie; Arènes décisoires; Politique fiscale; Bureaucratie.

Le texte analyse les caractéristiques de la politique fiscale dans le gouvernement Lula, mettant en avant son contenu et son style de prise de décisions, dans une perspective comparée, c'est-à-dire, en les confrontant à celle des gouvernements précédents, mais aussi à celles de ses deux mandats. L'analyse est contextualisée dans le cadre des défis posés par l'insertion du Brésil à l'économie mondiale et par l'expansion des demandes sociales permises par le nouvel ordre démocratique. Il montre que malgré les limites imposées par les marchés financiers qui exigent la crédibilité financière face aux investisseurs et, par conséquent, des contraintes budgétaires et des niveaux élevés d'excédents primaires, il y a place pour que la politique budgétaire s'oriente vers d'autres objectifs: stimuler la croissance et l'expansion de la demande intérieure par des programmes de transfert de revenus. Cela a été, en grande partie, possible par l'expansion des arènes décisoires gouvernementales et par l'adoption d'un style plus négocié de la prise de décision. 